\title{
Alandan Notlar
}

\section{Yaşlılarda sağlık hizmetlerine ve sosyal hizmetlere erişim sorunları}

\author{
Elife Göksala, Kayıhan Palab \\ a Dr. Uludağ Üniversitesi Tıp Fakültesi Halk Sağlığı Anabilim Dalı, Bursa \\ b Prof. Dr., Uludağ Üniversitesi Tıp Fakültesi Halk Sağlığı Anabilim Dalı, Bursa \\ Geliş tarihi: 16.09.2014, Kabul tarihi: 29.09.2014

\section{Özet} \\ $\mathrm{Bu}$ yazıda, yalnız yaşayan, yaşlı ve engelli bir hastanın sağlık ve sosyal \\ hizmetlere erişimi açısından yaşadığı sorunlar ele alınmış ve hizmetler \\ açısından neler yapılması gerektiği tartışılmıştır. Hastanın aile hekimliği \\ sisteminde yok sayılmış olması, ileri tarihe verilen randevular ve kullanıcı \\ ödentisi belli bașlı sorunlardır. Sağlık ve sosyal hizmetler arasında büyük bir \\ kopukluk söz konusudur. Aktif yaşlanmanın desteklenmesi için sağlık ve \\ sosyal hizmetler entegre olarak kamu tarafından erişilebilir ve ücretsiz olarak \\ sunulmalı, kapsamlı bir yaşlı izlemi programı uygulanmalıdır.
}

Anahtar Kelimeler: Sağlı hizmetleri, sosyal hizmetler, aile hekimi, engellilik.

\section{Problems of access to health care and social services for the elderly}

\begin{abstract}
In this article, challenges experienced by an elderly and disabled patient living alone were addressed in terms of access to healthcare and social services and were discussed from the point of view of what needs to be done to the services available to the patients. Problems included not cover under the family physician system, user fees, and delays for needed hospital appointments. There was a lack of coordination between the healthcare and the social services. To support an active life for the elderly, integrated healthcare and social services should be accessible, free of charge and provide a comprehensive follow up program.
\end{abstract}

Key Words: Health care services, social services, family physician, disability.

Sorumlu Yazar: Elife Göksal, Uludağ Üniversitesi Tıp Fakültesi Halk Sağlığı Anabilim Dalı, Bursa, E mail: elifegoksal@gmail.com

Turk J Public Health 2015;13(1) 


\section{Giriș}

Yaşlılığın sağlıklı bir biçimde sürdürülebilmesi için "aktif yaşlanma" politikalarının benimsenmesi önemlidir. Aktif yaşlanmanın desteklenmesi, sağlık sistemlerinin yaşam boyu sürecek bir izdüşüm ile sağlığın geliştirilmesine, hastalıklardan korunmaya ve birinci basamak ile uzun dönem bakım hizmetlerine eşit erişimin sağlanmasına odaklanması ile mümkündür. Sağlı ve sosyal hizmetlerin entegre, eşitlikçi ve maliyet-etkin olması gerekir. ${ }^{1}$

Sosyal hizmetler; kiși ve ailelerin kendi bünye ve çevre şartlarından doğan veya kontrolleri dişında oluşan maddi, manevi ve sosyal yoksunluklarının giderilmesine ve ihtiyaçlarının karşılanmasına, sosyal sorunlarının önlenmesi ve çözümlenmesine yardımcı olunmasını ve hayat standartlarının iyileştirilmesi ve yükseltilmesini amaçlayan sistemli ve programlı hizmetler bütünü olarak tanımlanmaktadır.

Ülkemizde sosyal hizmet kavramının kurumsallaştırılmasına yönelik ilk adım 1963 yılında Sağlık ve Sosyal Yardım Bakanlığı (SSYB) bünyesinde Sosyal Hizmetler Genel Müdürlügü̆nün kurulmasıyla atılmıştır. Daha sonra 1983 yılında 2828 sayılı kanunla Sosyal Hizmetler ve Çocuk Esirgeme Kurumu kurulmuş, kurum ilk başlarda SSYB'ye, daha sonra Başbakanlığa, hemen ardından Çalışma ve Sosyal Güvenlik Bakanlığı'na ve daha sonra tekrar Başbakanlığa bağlanmıştır. Günümüzde sosyal hizmetler Aile ve Sosyal Politikalar Bakanlığınca yürütülmektedir.

Ülkemizde sağlık hizmetleri ile sosyal hizmetler arasında her hangi bir entegresyon bulunmamaktadır.

\section{Olgu tanımı}

Hasta 66 yaşında bir erkektir. Kırk yıl önce bir kireç fabrikasında işçi olarak çalıştığı sırada geçirdiği trafik kazası nedeniyle her iki bacağı uyluk proksimalinden ampüte olmuştur. Geçirilmiş mide ve katarakt ameliyatı vardır. Anemi ve hipertansiyon hastasıdır. 30 paket/yıl sigara içme öyküsü bulunmaktadır. Tek başına yaşayan hasta, sakatlığı sebebiyle malulen emekli olmuş, evinde ayakkabı tamiri yaparak geçimini sağlamaktadır. Okuryazar olan hasta eşinden yirmi yıl önce ayrılmıştır ve 26 yaşındaki tek çocuğu şehir dişında üniversite öğrencisidir.

Hasta Bursa Nilüfer'de Fethiye Mahallesi'nde yaşamaktadır. Fethiye Mahallesi, Uludağ Üniversitesi ile Nilüfer Belediyesi arasında bir işbirliği protokolü ile kurulan Nilüfer Halk Sağlığı Eğitim ve Araştırma Bölgesi (NHSEAB) kapsamında yer almaktadır. Hasta 65 yaşının üzerinde olduğundan NHSEAB yaşlı izlemi programına alınmış ve mahallenin halk sağlığı hemşiresi tarafından düzenli aralıklarla evinde ziyaret edilmektedir.

Hastanın on yıldan uzun süredir yaşadığı ev Nilüfer Belediyesi tarafından mahalledeki parkın içinde yaptırılmıştır. Bir oda, bir tuvalet ve girişten oluşan evin su ve elektrik giderleri Belediye tarafindan karşılanmakta, ısınma elektrikli soba ile sağlanmaktadır.

\section{Klinik süreç ve girişimler}

11.01.2013 tarihindeki ilk ziyaret sırasında hastanın ses kısıklığı yakınması olduğu halde bir sağlık kuruluşuna başvuramadığı anlaşılmıştır. $\mathrm{Bu}$ yakınma nedeniyle hasta kulak burun boğaz (KBB) muayenesi için bir devlet hastanesine götürüldü ve önce $\mathrm{KBB}$, ardından $\mathrm{KBB}$ uzmanının yöneltmesiyle göğüs cerrahisi ve kalp damar cerrahisi (KDC) polikliniklerinde muayene edildi. Yapılan tetkikler sonrasında aort anevrizması tanısı koyuldu ve üçüncü basamak bir hastanede ameliyat olması önerildi.

Ameliyat sonrasında evde sağlık hizmetlerinden yararlanabilmesi amaciyla aile hekimine ulaşılmaya çalışıldı, ancak 
hastanın aile hekimine kaydı olmadığı anlaşıldı. Hastanın öncelikle en yakın aile sağlığı merkezine kaydı yapıldı ve hastalığı hakkında aile hekimine bilgi verildi.

Hasta tedavi için Uludağ Üniversitesi Tıp Fakültesi'ne (UÜTF) götürüldü. UÜTF KDC polikliniğinde muayene olan hastaya önce stent takılmak istendi. Ancak yapılan tetkikler sonrasında stent takılmasının uygun olmadığına karar verildi ve akciğerlerinde kitle tespit edilmesi üzerine hasta Gögüs Hastalıkları Anabilim Dalı'na devredildi. Hastaya burada kronik tıkayıcı akciğer hastalığı (KOAH) tanısı kondu ve kitlenin araştırılması amacıyla bronkoskopi ile biyopsi alındı. Biyopsi sonucuna göre kitlenin malign olmadığı anlaşıldı ve hasta taburcu edildi.

Nefes darlığının artması vestridor gelişmesinin ardından hasta UÜTF KBB polikliniğinde değerlendirildi; larenks kanseri tanısı konularak bir ay sonrası için operasyon planlandı ve trakeostomi açıldı. Nefes darlığı şikayeti süren hasta Gögüs Hastalıkları kliniğine yatırıldı. Yattığı sırada ek olarak depresyon ortaya çıkması üzerine hasta KBB tarafindan yeniden değerlendirildi ve ameliyat günü beklenmeden opere edildi. Operasyon sonrasında hasta sesi tamamen kısılmış olarak taburcu edildi.

\section{Sağlık ve sosyal hizmetlerin değerlendirilmesi}

Hem fiziksel engeli hem de ekonomik koşulları nedeniyle sorun yaşayan hastanın sağlık kuruluşlarına ulaşımı her seferinde NHSEAB yönetimi tarafından sağlandı. Oğlu ilk zamanlarda hastaya refakat ederken, tetkik ve tanı koyma sürecinin uzaması nedeniyle bir süre sonra babasına eșlik etmeyi bıraktı ve poliklinik muayeneleri ile tetkikler sırasında hastaya NHSEAB'de görevli bir sağlık çalışanı eşlik etti. Hastaya eşlik etmek ile ilgili sorunlar UÜTF'de yattı̆̆ sırada da sürdü. Oğlu babasının yanında kalmak istemediği için klinik sorumlusu hemşireler ile işbirliği yapılarak hastanın gereksinimleri giderilmeye çalışıldı.
Hastanın devlet hastanesinden UÜTF'ye ve UÜTF'de bölümler arasındaki sevkler, konsültasyonlar ve tetkik randevuları sırasında aksaklıklar yaşandı. Hastanın randevularının çok ileri tarihlere verilmesi üzerine bölümlerle görüşme yapılarak randevuları öne alındı.

UÜTF'de yatan hastalardan günlük ücret alınması hastanın yatış ve taburcu işlemleri sırasında çözülmesi gereken bir diğer sorun olarak ortaya çlktı. Hastane yöneticilerine hastanın Sağlık Uygulama Tebliğinde yer alan muafiyetlerden yararlanması gerektiği açıklandı ve yatak ücreti ile ilgili sorunlar çözüldü.

Gereksinim duyduğu tıbbi cihazların (Aspiratör ve nebulizatör) raporları da verilerek taburcu edilmesine karşın, hastanın oğlunun SGKişlemlerini yapmaması nedeniyle tıbbi cihazlar SGK aracılığıyla karşılanamadı. Hastanın solunum güçlügünün artması üzerine söz konusu tıbbi cihazlar NHSEAB yönetiminin girişimiyle Belediye tarafından sağlandı.

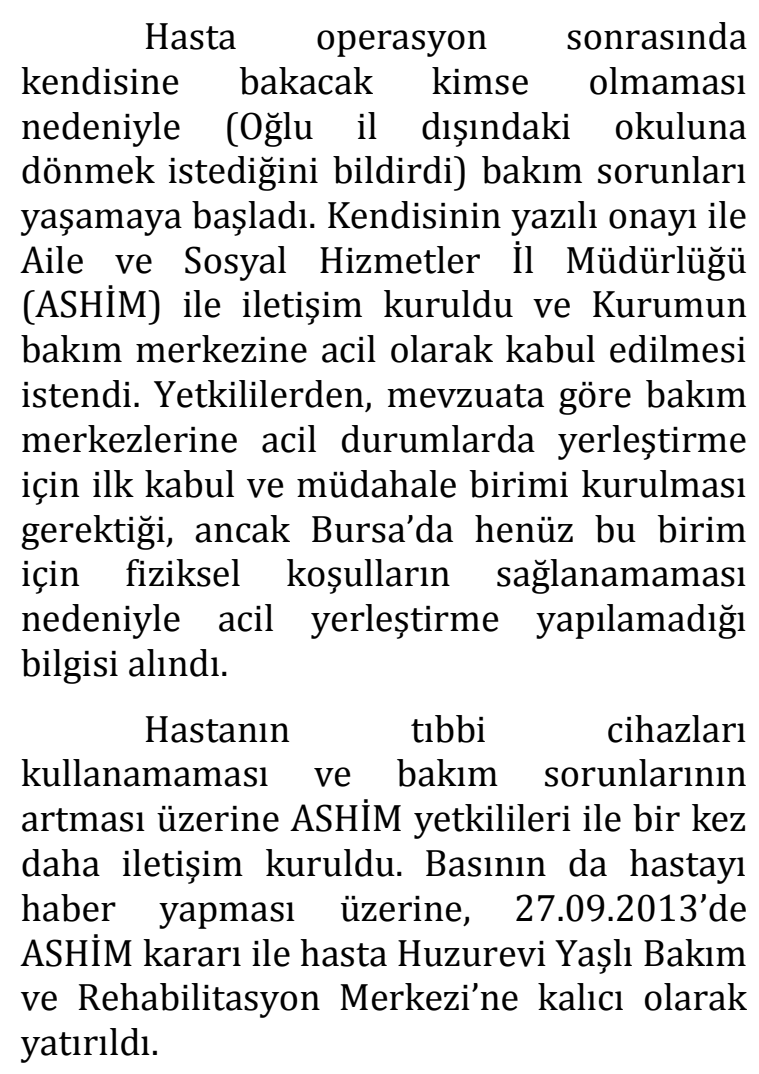
yatirıldı. 


\section{Sonuç ve öneriler}

$\mathrm{Bu}$ olgu, yalnız yaşayan yaşlı ve engelli bir hastanın sağlık ve sosyal hizmetlere erişimi sırasındaki zorlukların bir bölümünü göz önüne çıkarması bakımından önemlidir.

Hastanın engeli nedeniyle yardımsız olarak bir sağlık kuruluşuna başvurması olanaksızdır ve hem eșlikçi hem de ulaşım aracı gereksinimi bulunmaktadır. Sağlık hizmetlerine erişim sırasında hastanın aile hekimliği sisteminde yok sayılmış olması, ileri tarihe verilen randevular, hastalardan alınan ücretler ve cihaz temini sırasında yaşanan karmaşık SGK işlemleri sorun oluşturmaktadır.

Sağlık ve sosyal hizmetler arasında büyük bir kopukluk söz konusudur. Sosyal hizmet uzmanistihdam edilmediği için, hastanın tıbbi sosyal hizmetlerden nasil yararlanabileceğine ilişkin UÜTF'de bile hiç kimseden bilgi alınamamıştır.

Hasta NHSEAB kapsamında olduğu için yaşlı izlemi programına alınmışve bir sağlık sorunu ortaya çıktığında sağlık kuruluşlarına başvurusu başarı ile yönetilmiştir.

Aktif yaşlanmanın desteklenmesi için kamu tarafından sağlı ve sosyal hizmetlerin entegrasyonu ile ücretsiz, eşit ve erişilebilir bir yaşlı izlemi programı uygulanmalıdır.

\section{Kaynaklar}

1. Health And Ageing: A Discussion Paper, World Health Organization, WHO/NMH/HPS/01.1. 2001. 